\title{
LAS PEQUEÑAS RELACIONES DE DERECHOY LA JUSTICIA DE PAZ EN LAS COLONIAS AGRÍCOLAS DE MENDOZA (ARGENTINA), 1900-1910
}

AS PEQUENAS RELAÇÕES DE DIREITO E A JUSTIÇA DE PAZ NAS COLÔNIAS AGRÍCOLAS DE MENDOZA (ARGENTINA), 1900-1910

\author{
THE SMALL-CLAIMS LAW AND THE JUSTICE OF THE PEACE IN MENDOZA'S \\ AGRICULTURAL COLONIES (ARGENTINA), 1900-1910
}

\section{MÉDIATION ET JUSTICE DE PAIX DANS LES COLONIES AGRICOLES DE MENDOZA} (ARGENTINE), 1900-1910

阿根廷门多萨省的农业殖民地的法制和治安法官的作用, 1900-1910

DOI: 10.5533/1984-2503-20146102

Inés Sanjurjo de Driollet ${ }^{1}$

\section{RESUMEN}

Las colonias agrícolas del Sur de la provincia de Mendoza surgidas luego de la "campaña del desierto", gracias a las cesiones de agua de los ríos y el loteo de terrenos en los que se instalaron criollos e inmigrantes, mostraron una intensa vida comunitaria. El trabajo estudia la actuación de la justicia de paz en esa sociedad local, institución que estuvo en manos de jueces legos que tuvieron un conocimiento práctico del derecho, en un período de plena vigencia de la cultura del código. Los casos sustanciados ante estos juzgados muestran el éxito de esta institución en la resolución de los conflictos vecinales, que puede caracterizarse como benevolente, por la búsqueda de la conciliación entre las partes y priorizar el bien común sobre lo justo y la exactitud procesal, sin dejar de lado su función correccional cuando se lo consideró necesario.

Palabras-clave: Colonias agrícolas, justicia de paz, Mendoza.

\footnotetext{
${ }^{1}$ Profesora de la Universidad Nacional de Cuyo. Investigadora del Instituto de Ciencias Humanas, Sociales y Ambientales (INCIHUSA), Consejo Nacional de Investigaciones Científicas y Técnicas (CONICET), Argentina. E-mail: isanjurio@mendoza-conicet.gov.ar.
} 


\section{RESUMO}

As colônias agrícolas do sul da província de Mendoza surgidas logo após a "campanha do deserto", graças às cessões de água dos rios e ao loteamento de terrenos nos quais se instalaram criollos e imigrantes, mostraram uma intensa vida comunitária. O trabalho estuda a atuação da justiça de paz na sociedade local, instituição que esteve em mãos de juízes leigos que tiveram um conhecimento prático do direito, em um período de plena vigência da cultura do código. Os casos substanciados diante destes tribunais mostram o êxito desta instituição na resolução dos conflitos da região, que pode se caracterizar como benevolente, pela busca da conciliação entre as partes e priorizar o bem comum sobre o justo e a exatidão processual, sem deixar de lado sua função correcional quando se julgou necessário.

Palavras-chave: Colônias agrícolas, justiça de paz, Mendoza.

\section{ABSTRACT}

The agricultural colonies in the south of the province of Mendoza to have emerged upon the "Desert Campaign" - thanks to assignments of river water and the division of land in which criollos and immigrants were installed - demonstrated a rich community life. This work studies the actions of the justice of the peace - an institution led by lay judges with a practical knowledge of law in local society - in a period of full vigilance of the culture of the code of law. The cases heard before these tribunals demonstrate the success of this institution in resolving conflict in the region, which may be characterized as benevolent, due to its search for conciliation between the parties and prioritization of the common good over strict legal procedure, without compromising its correctional functions when deemed necessary.

Key words: Agricultural colonies, justice of the peace, Mendoza.

\section{RÉSUMÉ}

Les colonies agricoles du sud de la province de Mendoza, qui ont fait leur apparition suite à la "Campagne du désert " - par l'entremise de la cession des eaux de rivières et de la délimitation de terrains pour l'installation des criollos et des immigrants -, ont vu se développer une vie communautaire intense. Cet article étudie le rôle de la justice de paix 
dans la société locale, une institution qui était aux mains de juges non-professionnels disposant d'une connaissance pratique du droit, en pleine période de primauté du code juridique. Les cas présentés auprès de ces tribunaux ont montré l'efficacité de cette institution dans la résolution des conflits de la région. Cette institution peut être considérée comme bienveillante, en recherche de la conciliation entre les parties, avec une priorité donnée au bien commun plus qu'à l'exactitude procédurale, sans toutefois laisser de côté la fonction correctionnelle lorsque cela a été jugé nécessaire.

Mots-clés : Colonies agricoles, justice de paix, Mendoza.

\section{摘要}

阿根廷门东萨省南部农业殖民地出现较晚, 经历了“沙漠战役”, 由于引河灌溉和土地划分的措施, 吸引 了土生混血人和外来移民, 产生了浓烈地方色彩的社区生活。本论文研究了当地治安法官的工作状况, 治安法官是个办事机构, 在初期由懂法律的平民担任, 按照古老的治安条例进行管理。从判决的案例可 以看出,这些机构在解决当地的矛盾和冲突方面是成功的, 体现了其仁慈, 为整体利益而妥协的精神, 强 调的是共同利益, 而不是程序的公正和准确。当然, 当发现程序错误时, 机构的纠错功能也是不能被忽 视的。

关键词: 农业殖民地, 治安法官,门多萨

\section{Introducción}

La crisis del Estado Nación ha dado lugar al protagonismo de dos ámbitos diferentes pero relacionados: el orden global y los espacios locales o regionales. Frente a los procesos de globalización han surgido a fines del siglo $X X$ teorías comunitaristas que critican al liberalismo su tendencia al marcado individualismo. Dentro de ellas, Asladair Maclntyre defiende la capacidad de las pequeñas comunidades de brindar la dimensión adecuada para el desarrollo de prácticas sociales que privilegian el bien comunitario frente a la aplicación 
férrea del derecho positivo. ${ }^{2}$ En Tras la virtud, el filósofo escocés trató de explicar el "lugar que ocupan las virtudes, entendidas en el sentido aristotélico, situándolas en el marco de las prácticas sociales, de la vida de los individuos y la vida de las comunidades". ${ }^{3}$ En las comunidades se puede construir a través de las prácticas una moral realmente capaz de movilizar a los individuos en torno a un proyecto en común; ellas constituyen el contexto en el cual es evaluada la moralidad de los actos. Las distintas prácticas se ordenan a la consecución del bien común y para cada una hay quienes se especializan "mediante el cultivo de las virtudes necesarias para conseguirlo", lo que da pie a "una división moral del trabajo y cada parte de la sociedad tiene que depositar su confianza en las otras". 4

$\mathrm{Si}$ bien MacIntyre propone una forma de vida alternativa para las sociedades occidentales capitalistas de hoy, algunos de sus desarrollos son esclarecedores en ciertos abordajes históricos, como el estudio de la justicia de paz en San Rafael (provincia de Mendoza, Argentina) en el paso del siglo XIX al XX. ${ }^{5}$ Allí se instalaron varias colonias agrícolas a corta distancia de la villa cabecera del departamento, en tanto que a mayor distancia, al sur y en la zona fronteriza con Chile, había población dispersa. Pasar revista al proceso de colonización permitirá obtener una idea de las connotaciones que fue adquiriendo la sociedad sureña, para explicar mejor la actuación de la institución.

A lo largo del siglo XIX en Mendoza se pasó de unos magistrados rurales legos de raíces indianas -con funciones jurídicas y de policía- a la moderna justicia de paz que, acorde con la división de poderes propia del constitucionalismo liberal, ejercía funciones exclusivamente judiciales. ${ }^{6}$ Sin embargo, persistían notas de los antiguos magistrados: seguían siendo legos -que, aunque debían saber leer y escribir, carecían de un aprendizaje

${ }^{2}$ García de Madariga, Manuel (2002). La crítica al concepto liberal de justicia en la filosofía de Asladair MacIntyre, Memoria para optar al grado de doctor, Madrid: Facultad de Derecho, Universidad Complutense, p. 47.

${ }^{3}$ Macintyre, Asladair (1999). "Prefacio". In Animales racionales y dependientes, Barcelona: Paidos, p. 10.

${ }^{4}$ García de Madariaga, M. (2002). Op. cit., p. 557.

${ }^{5}$ Agradezco los comentarios realizados a conclusiones parciales presentadas en las XXIV Jornadas de Historia del Derecho Argentino, Mendoza, 2012, y de la Dra. Alicia Sarmiento.

${ }^{6}$ Sanjurjo, Inés (2010a). "Justicia de paz y cultura jurídica en el largo siglo XIX en Mendoza (Argentina). El caso del departamento de San Rafael en el sur provincial". In Nuevo Mundo Mundos Nuevos, Debates. URL http://nuevomundo.revues.org/59257. Consultado 20-4-2012. Sanjurjo, Inés (2010b). "La institución de la justicia de paz: la resolución de controversias vecinales de menor cuantía en materia civil y comercial (San Rafael, Mendoza, 1900-1916)". In Revista de estudios histórico-jurídicos, n. 32, Valparaíso-Chile, p. 395-418. 
formal del derecho propio de letrados-, y fallaban según su "leal saber y entender de acuerdo con lo alegado y probado por las partes"; si bien matizado con la prescripción de "ajustar sus sentencias a derecho", según mandaban los códigos provinciales de Procedimientos en materia Criminal de 1894, y de Procedimientos en materia Civil y Comercial de 1895 . $^{7}$ Frente a la condición de "no letrada" o lega de la justicia de paz -aunque no ajena al proceso codificador de la época- surge, entre otras cuestiones, el interés en ahondar en la especialización o "profesionalización" de ciertos roles cumplidos en ese ámbito por "abogados" y auxiliares también legos, y en el reconocimiento social que pudieron tener.

Para la elección de los jueces la municipalidad presentaba una terna al Ejecutivo provincial, aunque la Constitución provincial aclaraba que eran "funcionarios exclusivamente judiciales y agentes de los Tribunales de Justicia". ${ }^{8}$ Si bien esto último era una muestra de la especialización a la que se tendía en materia de justicia de paz -que con el tiempo quedaría totalmente dentro de la órbita del Poder Judicial- la intervención municipal en la elección hacía a la cercanía con la comunidad local. La institución constituía en este sentido una verdadera "justicia de proximidad", una cuestión que ha sido objeto de recientes preocupaciones jurídicas, políticas e historiográficas, en las que se plantea la necesidad en materia de justicia de facilitar la accesibilidad geográfica, social y temporal, por un procedimiento abreviado (más sencillo y menos costoso). Darío Barriera se refiere a las preferencias por estos jueces "próximos" en las sociedades locales; incluso aquella justicia señorial corporizada en hombres cercanos -suprimida en Francia por la revolución, por ser considerados dichos jueces "mecanismos de dominación"- fue preferida por la población

\footnotetext{
7 "Código de Procedimientos en materia Civil y Comercial de la Provincia de Mendoza". In Larrea, Basilio y Benzoni, Bernardo (compiladores) (1925). Compendio de leyes usuales de la Provincia con todas las modificaciones introducidas hasta el 30 de diciembre de 1924, t. XVIII, Mendoza: Publicación Oficial, p. 91 ss.; "Código de Procedimientos en materia Criminal de la Provincia de Mendoza". In Larrea, B. y Benzoni, B. (Compiladores) (1925). Op. cit., p. 463-685. La codificación fue un proceso que se dio en todas las provincias argentinas, que debieron actualizar su sistema procesal de acuerdo con los códigos civil, penal, comercial y de minería sancionados en el orden nacional a partir de 1869. Tau Anzoátegui, Víctor (1977). La codificación en la Argentina, Buenos Aires: Instituto de Historia del Derecho Ricardo Levene, p. 348 y ss.; Abásolo, Ezequiel (2004). "Las notas de Dalmacio Vélez Sárfield como expresiones del 'ius commune' en la apoteosis de la codificación, o de cómo un código decimonónico pudo no ser la mejor manifestación de la 'Cultura del Código'”. In Revista de Estudios Histórico-Jurídicos, n. 26, Valparaíso.

${ }^{8}$ Constitución de Mendoza de 1894/95, Archivo General de la Provincia de Mendoza (en adelante: AGPM), Independiente, Leg. 21, Carpeta 26.
} 
rural, según se ha revisado: "la justicia señorial, primer grado de jurisdicción, era la única forma de justicia posible para la mayor parte de la población francesa, que vivía en el campo y era campesina".

El presente estudio se inscribe en la línea de los estudios histórico jurídicos que en las últimas décadas han superado la perspectiva legal basada en la sola exégesis de la legislación positiva, predominante hasta bien pasada la mitad del siglo XX; al tiempo que se aleja de las reflexiones que desde las ciencias sociales tuvieron al derecho como un simple reflejo de lo económico, lo social y lo cultural. El derecho es un problema en sí mismo; pero también constituye un espacio de intersección de las historias política, social y económica, por lo que la historia del derecho actualmente se abre al trabajo interdisciplinario y a la renovación metodológica. ${ }^{10} \mathrm{Ha}$ incorporado el análisis de distintas variables, como las prácticas, que permiten comprender la dinámica de las instituciones, o la incidencia del espacio geográfico en el funcionamiento de éstas (de allí la necesidad de incluir datos cartográficos). ${ }^{11}$ Puede decirse que este estudio se vincula tanto con la historia del derecho como con la historia social, disciplinas que han transitado caminos separados, y actualmente han confluido en una historia social del derecho, que atiende a las prácticas sociales e institucionales y a la cultura jurídica de una sociedad, vale decir, a las actitudes, valoraciones y creencias que en relación al derecho son compartidas en una sociedad y que determinan la forma en que las personas se relacionan, como operadores o como público, con las instituciones y las normas jurídicas. ${ }^{12} \mathrm{Y}$, más puntualmente, puede hablarse de una historia social de la justicia: una historia de la relación entre justicia y sociedad, que investiga "las prácticas, los actores y las lógicas que articulan los sistemas judiciales", 13 así como las

\footnotetext{
${ }^{9}$ Barriera, Darío (2012). "Justicia de proximidad, pasado y presente, entre la historia y el derecho". In Polhis, n. 50, p. 53-55.

10 Mijangos, Pablo (2010). "La historiografía jurídica mexicana durante los últimos 20 años (Primera de dos partes)", Documentos de trabajo de CIDE, n. 69, México; Hespanha, Antonio M. (1993). La Gracia del Derecho. Economía de la Cultura en la Edad Moderna, Madrid: Centro de Estudios Constitucionales.

${ }^{11}$ Hespanha, Antonio (1989). Vísperas del Leviatán. Instituciones y poder político. Portugal, siglo XVII, Madrid: Taurus.

${ }^{12}$ Accatino Scagliotti, Daniela (1997). "El saber dogmático en nuestra cultura jurídica". In Revista de Derecho, n. 8, Valdivia: Universidad Austral de Chile, p. 7-18.

${ }^{13}$ Palacio, Juan M. (2005-2006). "Hurgando en las bambalinas de la paz del trigo: algunos problemas teóricometodológicos que plantea la historia judicial”. In Quinto Sol, n. 9-10, Santa Rosa-La Pampa, p. 99.
} 
formas en que estos han sido imaginados y percibidos por la sociedad a través del tiempo, y el efecto en las instituciones de diversos factores como las distancias, la distribución demográfica o los medios con que contaron los agentes de justicia para ejercer su ministerio. Por todo ello se ha considerado necesario abordar primero el proceso poblacional del sur mendocino, en el que la frontera indígena quedó atrás para dar lugar al surgimiento de prósperas colonias agrícolas, cuyo intenso movimiento social y económico contrastaba con los espacios más alejados y marginales del dilatado territorio.

Luego se estudiará el funcionamiento de la justicia de paz, ${ }^{14}$ lo que incluye tanto el conocimiento de la legislación vigente en el período (constitución provincial, códigos de procedimientos y de policía, leyes municipales, etc.) como el análisis de las prácticas institucionales a partir de datos brindados por expedientes de los juzgados -que obran sin catalogar en el archivo de la Circunscripción Judicial de San Rafael-, cuya no muy amplia cantidad solo permite un estudio de tipo cualitativo. Asimismo, se han tenido en cuenta los protocolos notariales.

\section{Proceso poblacional luego de la desaparición de la frontera indígena}

Por la característica semidesértica de la provincia la población se asentó en zonas regadas por ríos. Dos son los oasis principales: el del norte, de antiguo poblamiento, conformado por los ríos Mendoza y Tunuyán; y el del sur, conformado por el Diamante y el Atuel, que constituyó en el siglo XIX una avanzada en la frontera indígena. En este último se

\footnotetext{
${ }^{14}$ Sobre la justicia de paz desde diversas perspectivas en Argentina puede verse: Díaz, Benito (1959). Juzgados de Paz de Campaña de la Provincia de Buenos Aires (1821-1854), La Plata: Universidad Nacional de La Plata- Facultad de Humanidades; Garavaglia, Juan C. (1997). "Paz, orden y trabajo en la campaña: La justicia de Paz en Buenos Aires, 1830-1852". In Desarrollo Económico, n. 37; Yangilevich, Melina (2011). "La justicia de paz en la construcción estatal al sur del río Salado (Buenos Aires, 1ํ mitad del siglo XIX)". In Piazzi, Carolina (2011). Modos de hacer justicia. Agentes, normas y prácticas. Buenos Aires, Tucumán y Santa Fe durante el siglo XIX, Rosario: Prohistoria; Sedeillan, Gisela (2005). "La pérdida gradual de las funciones policiales del Juzgado de Paz: la creación de la institución policial en Tandil 1872-1900”. In Anuario Segreti, n. 5, Córdoba; Corva, M. Angélica (2005). "La Justicia de Paz en la Constitución de la provincia de Buenos Aires de 1873". In Revista de Historia del Derecho, n. 33, Buenos Aires; Yangilevih, Melina y Miguez, Eduardo (2010). "Justicia criminal y Estado en la frontera de Buenos Aires, "justicia criminal y Estado en la frontera de Buenos Aires, 1895-1880". In Boletín del Instituto de Historia Argentina y Americana Dr. Emilio Ravignani, n. 32, Buenos Aires; Paz Trueba, Yolanda (2008). "La justicia en una sociedad de frontera: conflictos familiares ante los juzgados de paz. El centro sur bonaerense a fines del siglo XIX y principios del XX". In Historia Crítica, n. 36, Bogotá, p. 102-123; Palacio, Juan M. (2004), La paz del trigo. Cultura legal y sociedad local en el desarrollo agropecuario pampeano (1890-1945), Buenos Aires: Edhasa.
} 
creó en 1857el departamento de San Rafael, que contaba hacia 1870 con un centro de población de relativa importancia: la villa de San Rafael, surgida al amparo del fuerte creado en 1806 a la orilla del Diamante. Al promediar la segunda mitad del siglo XIX este núcleo se encontraba en una situación de estancamiento por la limitada extensión de la terraza fluvial en que se erigía. Al este existía, en cambio, una extensa planicie en la que se habían establecido algunas estancias; ${ }^{15}$ allí, en el marco de la profundización de la lucha en contra del indígena, en 1872 el gobierno de la Nación hizo construir cuarteles (Cuadro Nacional) a donde se trasladó parte de la guarnición del viejo fuerte, instalándose también el 7ํㅜ Regimiento de Caballería. ${ }^{16}$

La presencia militar dio mayor seguridad a la zona, alentando la afluencia poblacional, aunque lo determinante fue la supresión del poderío indígena. Un abanico de colonias se establecieron en la planicie: Cuadro Salas, Cuadro Bombal, Colonia Francesa, Colonia Italiana, Colón (Balloffet); y otras al sur del río Diamante, como Rama Caída, Cuadro García y Cañada Seca. Tuvo gran empuje la llegada masiva de inmigración trabajadora del agro y la acción privada de empresarios, que adquirieron extensos terrenos con concesiones de agua y los canalizaron y lotearon para venderlos a pequeños propietarios, entre los que se contaban extranjeros y criollos. ${ }^{17}$ En 1903 el ferrocarril llegó a Colonia Francesa, lo que contribuyó a que se trasladara a ella la cabecera departamental, que pasó a llamarse Villa de San Rafael, en tanto que a la antigua sede de las autoridades se la llamó Villa 25 de Mayo. ${ }^{18}$ Los franceses constituyeron una colectividad pequeña (superada ampliamente por españoles e italianos en número), pero con un rol destacado gracias a su situación financiera y conocimientos de vitivinicultura. Por su parte, los españoles fueron la colectividad extranjera

\footnotetext{
${ }^{15}$ Denis, Paul (1969). "San Rafael. La ciudad y su región”. In Boletín de estudios geográficos, Vol XVI, № 6465, Mendoza: Facultad de Filosofía y Letras-Universidad Nacional de Cuyo, p. 231; Sanjurjo de Driollet, Inés (2006). "Frontera indígena y colonización agrícola". In Richard Jorba, Rodolfo et al. (2006). La región vitivinícola argentina. Transformaciones del territorio, la economía y la sociedad, 1870-1914, Buenos Aires: Universidad Nacional de Quilmes Editorial, p. 243 ss.

${ }^{16}$ Bustos Dávila, Nicolás (1983). "San Rafael. Ochenta años de la ciudad cabecera". In Los Andes, Mendoza, 110-83.

17 El gobierno vendió tierras fiscales y otorgó concesiones de agua correspondientes a los ríos Diamante y Atuel, por momentos de una manera tan excesiva que provocó críticas porque podía favorecer la gran propiedad en manos de una elite. Masini Calderón, José L. (1985). Mendoza y sus tierras y frontera del sur entorno a 1880 (1875-1885), Mendoza, p. 49-50.

18 San Rafael, San Rafael-Mendoza, 14-7-1905.
} 
más numerosa, quedando en segundo lugar los chilenos, que antes habían constituido el grupo no nacional más grande.

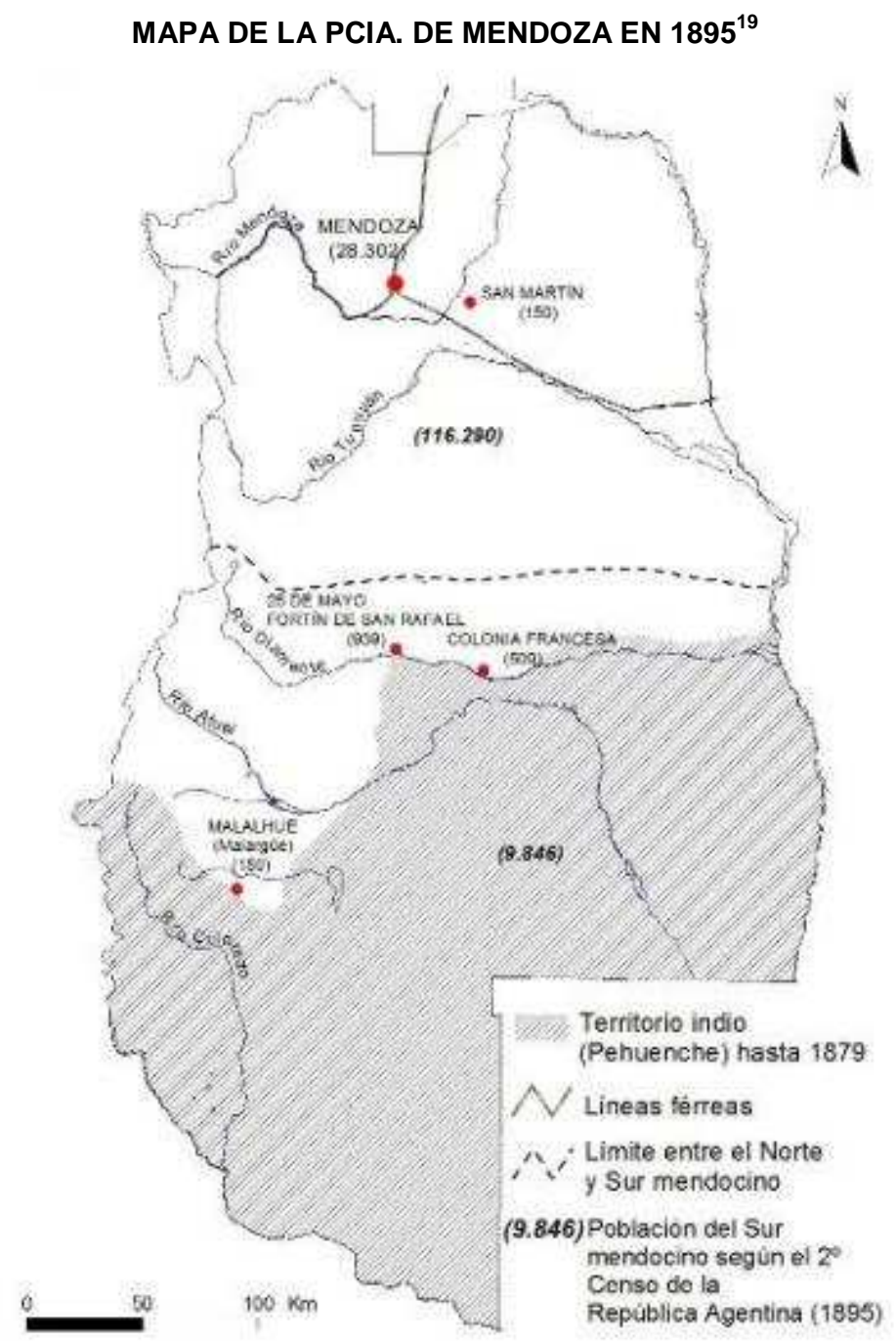

El oasis se fue poblando: en 1895 se contaron 9.846 habitantes en el departamento, de los cuales la planicie aportaba unos 1.600 y la villa 1000. Los pueblos establecidos al sur del Diamante rondaban 2.200 y el resto estaba distribuido en pequeños asentamientos en los

${ }^{19}$ Fuente: Denis, Paul (1969). Op. cit. Gentileza de Andrea Cantarelli. 
demás distritos. ${ }^{20}$ Otros núcleos surgieron en la zona delimitada por los ríos Atuel, Diamante y Salado; esos campos, que habían sido de los caciques Goico, fueron comprados por el Dr. Diego de Alvear y colonizados por su albacea, Ing. Carlos de Chapeaurouge. En 1902 había allí "ya más de trescientas familias de agricultores" que transformaban el desierto "en feraces campiñas"; 21 se buscaba que acudieran "hombres de capital y estancieros en la acepción moderna de la palabra". 22

Puede decirse que las colonias representaban "el progreso" promovido por las generaciones "constitucionalistas" del siglo XIX, debido a su intensa actividad socioeconómica y un componente sustancial de población europea; encarnaban el futuro, según la idea que se tenía de la zona: la "región del porvenir". ${ }^{23}$ La vida allí contrastaba con la situación de la población ubicada al suroeste: distante unos $180 \mathrm{~km}$ de la villa de San Rafael estaba la villa de Malargüe, erigida en 1886, que con sus 150 habitantes no presentaba gran desarrollo ni recibía los beneficios del gobierno municipal sanrafaelino, y tampoco contaba con juzgado de paz. En 1897 se estableció una comisaría en la villa y más tarde otra, a unos $180 \mathrm{~km}$ al sur, en el paraje del río Barrancas, zona limítrofe con Chile donde dominaba el cuatrerismo y tráfico de ganado. ${ }^{24}$. El distrito se caracterizó por su baja densidad poblacional, grandes propiedades en pocas manos y la presencia de puesteros en terrenos fiscales. Estos conformaban una comunidad de integración cultural argentino chilena con un fuerte componente indígena, que traspasaba la frontera nacional; con otros hábitos y otra economía, se dedicaban a la ganadería extensiva, principalmente caprina y ovina poco

\footnotetext{
20 Segundo Censo Nacional de la República Argentina, mayo 10 de 1895, t. I (1898), Buenos Aires: Taller Tipográfico de la Penitenciaría Nacional, p. 374-375.

${ }_{21}$ Ecos de San Rafael, San Rafael- Mendoza, 8-1-1902. Ver:. Seghesso de López, Cristina (1985). "General Alvear, departamento del sur mendocino (antecedentes y primeros años de vida)", Separata del Congreso Nacional de Historia sobre la Conquista del Desierto, Buenos Aires: Academia Nacional de la Historia, p. 225226.

${ }^{22}$ Ecos de San Rafael, San Rafael-Mendoza, 18-3-1903, y Alonso Camacho, Omar (1997). "Conflictos jurisdiccionales en departamentos del sur mendocino: 1914-1970", Separata del Sexto Congreso Nacional y Regional de Historia Argentina, Buenos Aires: Academia Nacional de la Historia, p. 392-393.

${ }^{23}$ En 1849, el periódico federal La llustración Argentina consideraba a estos territorios como "la principal riqueza de nuestro suelo" (La llustración Argentina, № 5, Mendoza, 1-10-1849). Tiempo después el escribano sanrafaelino Marcó del Pont lo señaló en su libro (Marcó del Pont, Augusto (1828). San Rafael, La región del porvenir, Mendoza: Impresiones Best). Pero ya en 1849 se consideraba a estos territorios como "la principal riqueza de nuestro suelo". La llustración Argentina, № 5, Mendoza, 1-10-1849.

${ }_{24}$ Maza, Juan I. (1985). Malargüe y su historia, Mendoza, p. 170 ss.
} 
especializada y transhumante. ${ }^{25}$ Esta era prácticamente la única actividad productiva, a diferencia de lo que sucedía en el oasis de San Rafael donde se inició una economía diversificada.

\section{La vida pública en las colonias}

Pronto comenzó a desarrollarse una activa vida pública en los nuevos poblados, favorecida por la llegada del ferrocarril, la apertura de comercios y servicios, la aparición de periódicos. En 1905, la prensa local se lamentaba de las escasas asociaciones existentes y alentaba a fundar un centro social cosmopolita, puesto que "aquí, donde todo el que trabaja prospera, es imperdonable que carezcan de un Centro Social donde reunirse y estrechar los vínculos de compañerismo [...] un centro social es una necesidad de orden hasta comercial". ${ }^{26}$ Sin embargo, no faltaban espacios de sociabilidad: unos con fines específicos (el Club Unión Agrícola, Comercial e Industrial de San Rafael y la Sociedad Recreativa Musical) y otros de carácter informal (el Club Hotel y “El Diamante Bar room”), ubicados en la nueva villa cabecera; así como aquellos más populares y arraigados en los pueblos rurales, como almacenes con venta de bebidas y canchas de carreras. $^{27}$

En cuanto a la participación política, sólo un pequeño grupo de importantes vecinos (empresarios, comerciantes, profesionales) tuvo un papel activo en el gobierno municipal; tanto argentinos como extranjeros, dado que estos últimos podían conformar un tercio del concejo deliberante. El voto calificado para concejales y la participación de los principales contribuyentes para sancionar el aumento de $\operatorname{tasas}^{28}$ fortaleció a ese círculo con asiento en el concejo, que tuvo no pocos enfrentamientos con el presidente de la institución, que era el jefe político y agente del Poder Ejecutivo provincial en el departamento. La elite local adquirió renombre en Mendoza, dado que mediante su accionar San Rafael se convirtió en el único departamento en el que el partido gobernante provincial -el civitismo- perdió en las

\footnotetext{
25 Debener, Marcela (2002). “Estado, frontera e integración regional: Neuquén-Mendoza 1880-1950”. In XIII Jornadas de Historia Económica, Mendoza, p. 15 (CD-rom).

${ }^{26}$ San Rafael, San Rafael-Mendoza, 1-3-05.

27 lbídem, 30-8-1905.

${ }^{28}$ Ley Orgánica de Municipalidades № 171 de 1900, Recopilación de Leyes desde 1896 a 1924, t. II, Mendoza, 1925, p. 557. 
elecciones de diputado de 1904, algo que constituyó una verdadera preocupación para el oficialismo. $^{29}$

\section{Los pequeños vínculos jurídicos y la justicia de paz}

Un artículo de la prensa mendocina decía sobre la justicia de paz:

(...) con arreglo a una ley sencilla y concreta produciría en las pequeñas relaciones de derecho que están bajo su amparo, beneficios prácticos y efectivos [...] aunque no lo parezca, la justicia tiene una alta misión que llenar en estos pueblos, en que los pequeños intereses se encuentran en tan gran número, y en que la fortuna se halla de todo punto subdividida. ${ }^{30}$

La alta misión de la institución sería, como lo dice su nombre, pacificar, conciliar, solucionar los conflictos y desavenencias concernientes a esas "pequeñas relaciones de derecho" forjadas entre los miembros de las comunidades locales, muchas veces de carácter casi doméstico. Tales vínculos surgían tácitamente de la misma convivencia y de una noción generalizada de justicia y de lo debido a cada uno en la comunidad local; ${ }^{31}$ y lógicamente del efecto de las leyes vigentes, así como de convenios de todo tipo. Estos frecuentemente tuvieron forma verbal: preacuerdos de compraventa, arreglos laborales, arrendamientos de vivienda, préstamos en mercadería o efectivo y otras cuestiones relativas a la marcha de la pequeña economía local, muchas de ellas casi domésticas. Era un ámbito en el que la palabra dada tenía valor, no sólo de honor sino también jurídico, como se observa en expedientes que son prácticamente las únicas fuentes que aportan datos sobre esa forma de vínculos. Asimismo, hubo situaciones y acuerdos -por lo general de un monto mayor- que quedaron formalizados ante el juez, que cumplió esta tarea de manera subsidiaria a la del escribano (por ausencia o por implicancia de este); la cantidad de protocolos muestra que hubo un gran interés en que quedaran formalizados de esta manera, como garantía para las partes. Entre ellos se destacan los contratos de plantación (de viñas, alfalfares, etc.), por los

\footnotetext{
${ }^{29}$ Sanjurjo, Inés (2007). "Formación de una elite de inmigrantes y criollos en el departamento de San Rafael (Mendoza) y su incidencia en la política provincial en el prolegómeno de la sanción de la Ley Sáenz Peña”. In Res Gesta, Rosario, p. 109 ss.

${ }^{30}$ El Constitucional, 6-1-1880.

${ }^{31}$ Macintyre, Asladair (2004). Tras la virtud, Barcelona: Crítica.
} 
que se manejaba una parte importante de la economía local, ${ }^{32}$ y otros convenios de tipo económico: compra-venta de diverso tipo, contratos de arrendamiento de vivienda o local, nombramiento de apoderado, préstamos, etc. Asimismo, quedaron asentados otros asuntos: incumplimiento de deberes conyugales y familiares, compromisos de matrimonio, otorgamiento provisorio de un menor en tenencia, anotación de nacimiento por ausencia del encargado del registro civil, etc. Tanto las prácticas en el ámbito de la justicia de paz como los acuerdos verbales y los protocolizados, fueron parte del universo de vínculos de derecho de esa sociedad, y se complementaban, constituyendo un aspecto central de la cultura jurídica local.

A principios de siglo existían dos juzgados: en la nueva Villa de San Rafael y en la Villa 25 de Mayo, ambas en la zona núcleo del oasis, al norte del departamento. Entendían en causas civiles de poco monto (hasta $\$ 200$ ), en juicios de sucesión de no más de $\$ 1000$ no habiendo cuestión sobre la calidad de los herederos, y en desalojos de casas y predios urbanos; y en causas criminales, en delitos considerados de gravedad menor: rapto con intención de casarse, amenazas, coacciones, violación de prostituta, descubrimiento de secretos, injurias leves, hurto y rapiña de no más de $\$ 50$, usurpación, estafa y daños no superiores a tal cantidad, y falso testimonio. ${ }^{33}$ En cambio, las causas por montos o delitos más graves debían sustanciarse en los juzgados de $1^{10}$ instancia en lo criminal y penal ubicados en la capital provincial, distante unos 240 km, los que también constituían instancia de apelación desde determinada suma en adelante. Quiere decir que ambos juzgados de paz eran la única magistratura en el inmenso territorio departamental. Los pasos a seguir en los juicios estaban estipulados en los códigos de procedimientos.

\section{Actuación en materia civil y comercial}

El Código de procedimientos en materia civil disponía que el juicio fuera verbal, salvo en causas sucesorias y concursos de acreedores. Lo actuado debía constar en un acta

\footnotetext{
${ }^{32}$ Cantarelli, Andrea (2009). "Contratistas de plantación: agentes geográficos en los comienzos de la viticultura moderna en San Rafael, Mendoza, (1880-1914)". In Anuario del Centro de Estudios Históricos "Prof. Carlos Segreti, v. 9, Córdoba, p. 239-262.

${ }^{33}$ Ley Orgánica de Tribunales de 18-9-1900, Registro Oficial de Mendoza.
} 
firmada por el magistrado y el demandante o un testigo si este no sabía firmar (esto ocurrió con frecuencia). La oralidad ciertamente preveía la agilidad del proceso que tradicionalmente fue atribuida por la doctrina a esta magistratura, colaborando con ello los cortos plazos impuestos para la sustanciación de los juicios; en tanto que las actas permitían el control de la actuación del magistrado y constituían una garantía para las partes.

Los juicios se originaban por demanda realizada por un particular, empresa o entidad de gobierno (comúnmente en este caso, por deudas fiscales). Por lo general los propios implicados solían realizar la defensa de sus intereses ante el juzgado sin necesidad de un defensor. Muchos expedientes sólo constan de la demanda, lo que sugiere que muy probablemente se llegó al acuerdo o conciliación en la primera audiencia, que era lo primero que debía buscar el juez, de allí que no fuesen necesarias otras citaciones, presentación de pruebas y fallo. El magistrado debía intentar la conciliación previamente al fallo, ayudando a las partes con imparcialidad. Solo luego, "si los litigantes no se arreglan y están conformes con los hechos alegados en la demanda y en la contestación, el juez dará sentencia en el mismo acto si fuera posible, y en caso contrario dentro de cinco días emplazando a las partes para que comparezcan a oír sentencia”. ${ }^{34}$ Cuando no se lograba avenencia el juicio podía culminar con embargo y ejecución al deudor, pero si se lograba que este pagara finalmente, la medida no se hacía efectiva; en caso de deudas con un organismo de gobierno -como la municipalidad- lo común fue el embargo si no se cancelaba el total de lo adeudado, es decir que no había mucho lugar para arreglos.

Gran parte de los juicios trataron sobre disidencias surgidas en relación con contratos verbales, como se ha dicho. Un ejemplo es el relativo a la puesta en producción de un terreno por acuerdo entre el argentino Tolentino Funes y el italiano Antonio Di Fiore. ${ }^{35} \mathrm{El}$ primero inició el juicio "no siéndole posible ningún acuerdo amistoso", según dijo. Ambos habían convenido que Funes trabajara en dos terrenos de Di Fiore realizando una sementera de trigo y un potrero de alfalfa, y luego repartir el producido; sin embargo, terminada la cosecha hubo desacuerdo sobre la suma que tocaba a cada uno. Luego de la presentación

\footnotetext{
${ }^{34}$ Art. 544-554. "Código de Procedimientos en materia Civil". Op. cit.

${ }^{35}$ Expte. iniciado el 30-5-1903.
} 
del primero se apersonó el otro "para ponerse a derechas con Tolentino Funes en demanda por cumplimiento de un convenio entre ambos", pero fue el juez quien debió determinar que se repartieran lo obtenido en partes iguales después de sacar lo correspondiente al trillador. Así, el fallo solucionó el conflicto en el plazo de tres días, según la rapidez establecida para esta justicia ${ }^{36}$ y que generalmente se cumplió en los juicios civiles, tal como se advierte al revisar las fechas de inicio y finalización, y aun cuando no se hubiese llegado a la conciliación previa al fallo y debiesen presentarse pruebas y testigos. Esto contribuía al entendimiento entre vecinos y evitaba mayores pérdidas para las partes.

Un juicio iniciado en noviembre de 1901 en relación con un convenio escrito de arrendamiento y que no tuvo solución por conciliación, alargándose los tiempos, fue la causa iniciada por Francisco Alterio (italiano, 50 años, comerciante) contra su arrendatario, José Salomón. Este había subarrendado el inmueble a Luis Intergugliermo (italiano, 37 años, constructor), con quien Alterio ya había tenido un violento altercado por destrozos causados en la vivienda. ${ }^{37}$ Este temía que aquel reincidiese, por lo cual solicitaba se obligase a Salomón a hacer desalojar la habitación y a darle una garantía pecuniaria por el tiempo de estadía del subarrendatario. Presentados ambos en el juzgado, Salomón aceptó "previo arreglo" entregar la casa a fin de mes, pero luego hubo que emplazarlo para que lo hiciera, con apercibimiento de pago de $\$ 2$ por día de incumplimiento. Como llegó enero, mes de feria, Alterio pidió ser habilitado para litigar pues todavía no le entregaban la vivienda, y solicitó embargo de bienes de Salomón. El 2 de febrero el juez envió un oficial para realizar el desalojo de Interguglielmo, lo que se debió hacer con la fuerza pública. En cuanto al embargo solicitado, Salomón disponía solo de un carro con arneses para mulas, con lo que

\footnotetext{
${ }^{36}$ Entre la citación y el juicio debían mediar mínimo 3 días; si no se conocía el domicilio del demandado, aquélla debía publicarse tres veces en el periódico local, no debiendo pasar de 20 días la fecha de la audiencia. Producida esta, si no se lograba conciliación el juez debía fallar en ese mismo acto en lo posible, y no más de cinco días después. Si las partes alegaban hechos controvertidos, debía declararse el pleito a prueba por un tiempo no mayor de 20 días, prorrogándose si la prueba se hallaba a gran distancia. Si los testigos no pudiesen comparecer en un mismo día, se les debía tomar declaración lo más pronto posible. Vencido el período a prueba, el juez debía fallar dentro de los diez días. Art. 547 a 565, "Código de Procedimientos en materia Civil". Op. cit.

${ }^{37}$ En junio, Alterio había discutido con Interguglielmo por igual motivo, y sacando una pistola debajo del poncho le había disparado sin lograr herirlo. Como no hubo tentativa de homicidio y dado que aquel acusaba al otro de destrozar la casa que le arrendaba, el juez dispuso que se le impusiera la pena de arresto "por uso indebido de armas", conmutable a \$1 por día, según el Código de Policía de 1900.
} 
su deuda a Alterio fue saldada y pagados los gastos del juicio. En este caso, el proceso se alargó por incumplimiento de una de las partes.

Si bien todos podían presentarse a litigar -nacional o extranjero, hombre o mujer, y de cualquier condición social- la mayoría de los que lo hicieron en materia civil y comercial pertenecieron a sectores medios de la sociedad local, es decir, tenían algo que perder (pequeños propietarios, dueños de almacenes y otros negocios, arrendatarios, empleados, etc.). Muchos de los expedientes constan solo de la demanda, lo que sugiere que se logró la conciliación inmediatamente. ${ }^{38}$ Entre tantos ejemplos, puede citarse el de un compromiso de venta de un terreno mediando solo promesa verbal por parte de la propietaria, Luisa Jiménez, al futuro comprador, Tomás Lucero; en tal virtud este le hizo mejoras y siembras. Pero dado que ella luego pretendió venderlo a otro, Lucero la demandó e intimó a pagarle los gastos realizados por él. Como no hay más trámites, se presume que arreglaron en la primera entrevista.

\section{Actuación en materia penal}

El autor del Código Penal argentino definía el delito como "toda acción u omisión prevista y castigada por una ley penal que está en plena observancia y vigor", ${ }^{39}$ acorde con la tendencia del constitucionalismo liberal y el positivismo de limitar el arbitrio judicial. A la justicia de paz llegaban casos de delitos menores, que merecían no más de 3 meses de prisión: hurtos, injurias y heridas leves. En lo relativo a delitos contra la propiedad, se cuenta con juicios por daños, robos, extravíos, etc., dentro del monto de \$50. En cuanto a los juicios por lesiones, estuvieron involucrados la mayor de las veces jornaleros, peones, linieros, carreros, y frecuentemente debido al abuso en el consumo de bebidas alcohólicas. ${ }^{40}$ Un juicio de 1902 fue motivado por herida causada con cuchillo en una mano por un peón de carreta a otro mientras almorzaban junto a la tropa, luego de que este lo empujara a modo de broma; el reo fue condenado a un mes de prisión porque se había reconocido culpable y no obstante decir que estuvo ebrio. También entre los sectores medios hay casos de violencia

\footnotetext{
${ }^{38}$ Sanjurjo, I. (2010b). Op. cit.

39 Tejedor, Carlos (1871). Curso de Derecho Criminal, 2ํ Parte, Buenos Aires: Librería de C. Yoli, p. 19.

40 San Rafael, San Rafael-Mendoza, 30-09-1903.
} 
por diversas desavenencias, y contra la mujer en el ámbito familiar, aunque en menor cantidad.

El expediente se iniciaba con el sumario de prevención o policial realizado en la comisaría del distrito en el que ocurría el hecho -según establecía el Código de Policía de 1900- para lo cual debía haber prueba o semiplena prueba, o una denuncia. El trámite consistía en un cuestionario elaborado por el comisario, volcado en una especie de formulario, e incluía testimonio de los presuntos culpables y testigos, y todo aquello que pudiera ayudar a esclarecer el delito. Pasado el expediente al juzgado, frecuentemente con la opinión del jefe político -autoridad policial del departamento-, el magistrado podía realizar nuevo sumario si consideraba que el anterior tenía errores, pero lo corriente fue que este quedara. El juez nombraba fiscal cuando era delito que "diera lugar al ejercicio de la función pública", algo que no era estrictamente necesario "cuando el delito sólo pudiera perseguirse a instancia de parte legítima y ésta solicitase su castigo" (ofensas a la honestidad o al buen nombre, a la castidad conyugal, etc.). El mismo acusado podía realizar su defensa, o bien elegir defensor, que por lo general era nombrado por el juzgado porque los reos solían no conocer a alguien que los defendiese. Luego el juez convocaba a audiencia, a la que debían asistir aquél, el acusador -si lo hubiese-, los testigos y el procesado o su defensor, y llevar “las pruebas que tuvieren”. El proceso debía ser verbal -aunque debía constar en actas- y celebrado dentro de los tres días desde la aceptación del fiscal, "pudiendo prorrogarse [este plazo] a solicitud de parte y mediante causa bastante que estimará el juez" ${ }^{41}$

Los juicios penales finalizaban generalmente con el fallo del magistrado, y predominaba el modo paternalista para resolver controversias. En litigios sobre cuestiones poco graves esta justicia se caracteriza por una cierta clemencia, ya fuera porque el juez podía dar por "compurgada" la pena con los días pasados en prisión policial, ya porque la condonaba por distintos motivos, como no haber tenido el imputado antecedentes penales, o bien porque no dio necesariamente la razón a la parte patronal en juicios laborales. ${ }^{42}$ No

\footnotetext{
${ }^{41}$ Art. 415, "Código de Procedimientos en materia Criminal". Op. cit., p. 5849.

42 Entre muchos otros, muestran la benignidad de la justicia de paz los siguientes ejemplos:
} 
ocurría lo mismo en la etapa policial, en la que los agentes, sobre todo en los estratos más bajos de la institución -pertenecientes a los sectores sociales subalternos, precisamente entre los que se cometían la mayor cantidad de delitos según las estadísticas: jornaleros, peones, carreros- solían mostrar mayor dureza en el trato a los reos y en la interpretación de los hechos, actitud al parecer más frecuente con sujetos de su misma condición social.

El plazo establecido por la ley para el envío del sumario y acusados al juzgado fue poco cumplido y muchas veces el juez debió dar por satisfecha parte o el total de la pena con los días pasados en prisión en la etapa policial. ${ }^{43}$ Además, fueron frecuentes los abusos de autoridad por parte de la policía, pudiendo esta etapa tener para los inculpados un carácter punitivo "agregado", sobre todo en comisarías muy apartadas de la sede departamental. Ejemplo de ello es un juicio con sumario iniciado en la comisaría de la lejana localidad de Río Grande (ubicada al sur de Malargüe) por sustracción de mercadería realizada por empleados en el establecimiento comercial del italiano Egidio Casnati. ${ }^{44}$ Estos eran chilenos o hijos de chilenos, peones gañanes o jornaleros, cuyos padres eran "trabajadores de a pie" en otro establecimiento de Malargüe, o propietarios de algunas cabras. Luis Carrasco, de 18 años, principal acusado, declaró que había entrado dos veces a robar y "lo sorprendió el patrón", quien lo hizo encerrar en una pieza; y que llevó lo sustraído a la casa de sus padres sin que éstos supieran. Luego confesaron su participación otros dos, de 18 y 20 años. Nótese la extracción socioeconómica de los acusados y de sus progenitores, pertenecientes a la

Expte. iniciado por Dn. Enrique Fenconi, italiano, relojero, por robo de reloj, 1902. Es encontrado culpable Emilio Fuentes, quien devuelve el objeto y declara no haber sido procesado antes comprometiéndose a no dar más motivos para ser arrestado. El juez resuelve la condonación de la pena.

Expte. Don Pío Ara (español, dueño de la Casa Importadora-Almacén, Tienda y Ferretería" y acopiador de frutos del país) contra al trabajador Justo Sosa, por robo de un poncho en una de sus chacras, 1902. Luego de declaración de varios testigos, el juez resuelve no sancionar a Sosa, previa devolución del poncho, porque lo había sustraído en estado de ebriedad.

Expte. Dn. Pedro Lastra contra Dn. Agustín Pobrete por robo de su perro, 1904. Luego de exponer los testigos, el juez resuelve dejar libre al animal para que siga a quien sea su voluntad, estando ambas partes presentes.

${ }^{43}$ La detención de una persona por la policía debía realizarse ante un hecho con carácter de delito o que lo hiciera presumir, o si se exigiera la concurrencia de la persona para prestar declaración; pero debía durar mientras se practicasen las primeras investigaciones del sumario y por no más de 48 horas, salvo que resultasen complicados los declarantes en el hecho y bajo responsabilidad del funcionario que la hubiese autorizado. La detención se transformaba en prisión preventiva cuando quedaba justificada la presencia de delito al menos por semiplena prueba, pero esto debía ser establecido por el juez correspondiente (Art. 102, 103 y 104, "Código de Procedimientos en materia Criminal". Op. cit., p. 5719-20).

${ }^{44}$ Sumario iniciado en Río Grande, 1901. 
numerosa comunidad chilena existente en Malargüe. El envío del expediente y los tres detenidos al juzgado fue realizado 34 días después, excediendo en mucho el tiempo que llevaba cubrir la distancia desde Río Grande a la cabecera departamental. ${ }^{45}$ Ya ante el juez, el fiscal Pascual Ruiz dijo que los objetos hurtados no valían más de $\$ 50$, pues los reos habían devuelto parte al dueño; y que además habían confesado el hurto, por todo lo cual el caso no recaía en el juzgado del crimen de la ciudad (algo que hubiese significado una mayor dureza en el castigo). A continuación, solicitó 3 meses de arresto, pena máxima que podía imponer esta justicia. El juez hizo comparecer a los detenidos, a quienes, en cumplimiento del art. 123 del Código procesal les leyó la causa de la imputación ${ }^{46}$ y les hizo un nuevo interrogatorio en forma oral, en el que ratificaron lo declarado antes. Luego nombró defensor a José Santander, quien solicitó una pena menor que la solicitada por el fiscal con las siguientes razones:

\begin{abstract}
(...) que en el sumario de prevención no consta el denuncio o queja del damnificado en la sustracción de mercaderías que en él se mencionan, razón sin duda por el hecho de haberle sido devueltas, por lo que el delito se atenúa y sólo queda la acción pública que de oficio el juez debe castigar, pero no con el maximun [sic] de la Ley por cuanto ha habido negligencia por parte del damnificado en la seguridad de sus intereses, que ha descuidado obligando a la policía a hacer gastos en la remisión de los procesados a cuarenta leguas de distancia del asiento del juzgado. Debe también tenerse en cuenta la minoría de edad del iniciador, y que todos ellos han sido penados por el hecho de haber sido conducidos a esta villa [cabecera departamental] pudiendo haber sido castigados por las autoridades de aquel lugar.
\end{abstract}

Si bien no consta el fallo, es significativa la argumentación de la defensa, que encontraba un atenuante no sólo en el obrar del damnificado y la edad del iniciador, ${ }^{47}$ sino también en las penalidades del largo viaje (unos $250 \mathrm{~km}$ ) y en que "pudieron haber sido castigados por las autoridades de aquel lugar". Se entendía, pues, que la etapa policial podía cumplir una función punitiva -no contemplada por la ley-, y en esta ocasión no sólo por la cantidad de días que llevaban detenidos antes de presentarse ante el juez (poco más de un mes), sino también por los escarmientos que seguramente habían recibido los reos.

\footnotetext{
${ }^{45}$ Los plazos legales para el envío del expediente al juzgado eran de 48 horas después de iniciado el sumario en la Ciudad, 3 días en los departamentos rurales, y hasta 5 días si las distancias eran largas.

46 "Código de Procedimientos en materia criminal". Op. cit., p. 5729.

${ }^{47}$ La minoría de edad desde los 14 a los 18 años constituía un atenuante. Tejedor, C. (1871). Op. cit., p. 180.
} 
El caso es demostrativo del carácter benévolo de esa justicia frente a los rigorismos y excesos policiales; constituía un espacio en el que el reo podía ser escuchado y defendido, cualquiera fuese su condición social. ${ }^{48}$ Las penalidades conferidas sin sentencia previa constituían una falta a la ley, aunque prácticamente no había control sobre el accionar policial fuera de la posibilidad de que alguien realizara una "denuncia". En cuanto a los plazos establecidos para el envío del expediente al juzgado, quedaba a consideración del magistrado aplicar sanciones disciplinarias a los agentes que no hubiesen cumplido, si el retraso hubiese obstaculizado la investigación, según se aclaraba. ${ }^{49}$ No se han encontrado evidencias, sin embargo, de que se haya hecho este tipo de requerimientos a la policía.

Es de interés una denuncia realizada en la comisaría de Colonia Francesa contra el gendarme Julio Ortiz, por su comportamiento con el jornalero chileno José Salinas, de 52 años, cuando lo conducía arrestado a caballo. ${ }^{50}$ Entre otros, el testigo Aurelio Robledo, empleado de 19 años, dijo que vio a Ortiz empujando al hombre con un sable desenvainado y pegándole con un rebenque, y que este estaba ebrio y no se había desacatado. El comerciante suizo Pablo Grivel declaró que vio que pegaba con el rebenque al caballo llegando a golpear a Salinas, y que lo insultaba groseramente causando "la justa indignación de los que estaban viendo" cómo castigaba a un hombre "incapaz de hacer reacción a la policía". El comisario envió el sumario al jefe político, exponiendo que el "vigilante" Ortiz (argentino, 19 años) negó los hechos y pidió la baja; y que en su opinión había incurrido en abuso de autoridad, cuestión que "había suscitado muchas murmuraciones por parte del público que presenció la falta”. El expediente termina sin resolución, lo cual quizá se debió a

\footnotetext{
${ }^{48}$ La policía era una dependencia del Poder Ejecutivo con una actuación directamente vinculada a la justicia criminal, y cuyo accionar estaba reglamentado por el Código de Policía. La etapa policial en los juicios penales era considerada necesaria no obstante saberse que podía haber abusos: "dejar a la acción exclusiva de los funcionarios de esta repartición [la policía] sería desnaturalizar su misión, y hacer perder en muchos casos elementos preciosos para la investigación criminal, que sólo pueden ser apreciados por personas que reúnan la competencia de un Juez [...] Privarle a su vez de toda intervención [a la policía] en la verificación de los primeros pasos del juicio, sería hacer imposible asimismo en muchos casos el descubrimiento del delito y de los delincuentes, porque la Policía se encuentra en aptitud de ocurrir inmediatamente, sin la menor pérdida de tiempo, al lugar en que el delito se perpetra y verificar antecedentes y diligencias que más tarde tal vez sería imposible realizar". Nota del legislador Obarrio en oportunidad del envío de proyecto a la Cámara, "Código de Procedimientos en materia Criminal". Op. cit., p. 5673.

${ }^{49}$ Art. 15, Ibídem, p. 5678.

50 Sumario iniciado en Colonia Francesa, 1902.
} 
que el juez consideró suficiente la renuncia del agente. El rechazo y la denuncia por el abuso de autoridad entre los vecinos de la cosmopolita Colonia Francesa muestran la existencia de lazos solidarios en la sociedad de las colonias. ${ }^{51}$ Pero de los casos analizados se infiere que el maltrato fue más común en las comisarías más lejanas, tal como ocurrió con los peones que habían robado en la zona de Río Grande, pertenecientes a la población "de a pie" dedicada al pastoreo de ganado menor.

Un expediente es demostrativo de que el accionar policial en detrimento de los sectores subalternos podía realizarse de distintas formas. El sumario se inicia con la denuncia del capataz de una mina ${ }^{52}$ contra cinco operarios que se habrían fugado sin cumplir convenio de cuatro meses de trabajo, y ocultado herramientas. Luego aparecen las declaraciones de los trabajadores, mineros o jornaleros de entre 24 y 41 años, cuatro chilenos y un argentino. Uno de ellos, por ejemplo, dijo que tenía contrato pero el dueño no lo había cumplido, que había sido objeto de maltrato y presión a su libertad mediante ostentación de armas (máuseres argentinos, rifles y sables), y que como no se le permitía retirarse del trabajo lo hizo junto con los otros para presentarse ante la justicia y lograr la independencia; y, además, que su "libreta" de mercaderías estaba saldada. Las fechas de las declaraciones muestran que los trabajadores se presentaron primero para denunciar los malos tratos y como descargo por abandonar el trabajo, pero la policía concedió a la parte patronal la calidad de querellante, y a aquellos la de inculpados. Según Tejedor "la acusación resiste la contraacusación", pero se exceptuaban algunos casos, entre ellos "si el delito con que se reconviene o contraacusa es mayor"; 53 sin embargo, este no era el caso. El fiscal manifestó que no debió "procederse a la detención de los individuos" por no haber "causa suficiente ni prueba alguna" de que hubiesen "cometido delito alguno punible", pues no se había comprobado estafa ni el ocultamiento de herramientas denunciado, por lo que pidió la

\footnotetext{
${ }^{51}$ Respecto de esta participación ciudadana en el control de la justicia: Barreneche, Osvaldo (2007). “¿Lega o letrada? Discusiones sobre la participación ciudadana en la justicia de la ciudad de Buenos Aires durante las primeras décadas de independencia y experiencia republicana". En Palacio, Juan M. y Candioti, Magdalena (compiladores) (2007). Justicia, política y derechos en América Latina, Buenos Aires: Prometeo, p. 181-182. Sobre la prevalencia de la búsqueda del bien común sobre la exactitud procedimental en la justicia: García Pino, Gonzalo (2001). "La idea de derechos en Alasdair Maclntyre y Charles Taylor: un contrapunto comunitarista". In Revista Ciencia Política, Vol. XXI, n. 1, p. 14.

52 Sumario iniciado en Rama Caída, 1901, iniciado por denuncia de Luis Maturana Correa, capataz de mina.

53 Tejedor, C. (1871). Op. cit., p. 20.
} 
inmediata libertad de los inculpados. Los trabajadores quedaron libres; sin embargo, sus denuncias sobre el uso indebido de armas por el capataz no tuvieron efecto judicial.

La actitud de los jueces, sobre todo en juicios de familia y estando implicados menores, tuvo un carácter paternal y un modo muchas veces salomónico de resolver los conflictos, no sin reprensiones a los padres para que asumiesen sus responsabilidades con la prole. Fue mucho más estricta la actuación cuando mediaron hechos de sangre o violencia familiar, dando lugar incluso al divorcio cuando hubo maltratos hacia la mujer. Tal el caso de Emilia Videla (argentina, 40 años, dueña de casa) contra su esposo, Felipe Gamboa (chileno, 41 años, agricultor y propietario), por malos tratos y lesiones en presencia de los hijos. ${ }^{54} \mathrm{La}$ reincidencia de éste hizo que el juez le impusiera tres meses de cárcel o una suma equivalente declarando "a salvo los derechos de la esposa para que recurra donde corresponda en demanda de divorcio". ${ }^{55}$ Se trató de una pena más rigurosa que la aplicada en la mayoría de los juicios con condena de cárcel (generalmente de un mes) con que se cuenta.

Hubo juicios penales en los que se logró la conciliación, y en ello se advierte buena voluntad de la parte afectada. El juicio iniciado con una denuncia de Bernardino Izuel (español, 49 años, de Costa del Atuel, propietario, comerciante y constructor de obras de irrigación) es demostrativo de ello. ${ }^{56}$ Izuel había enviado a la capital provincial una carga en carros suyos al mando de Patrocinio Bilurón (argentino, soltero, 27 años, capataz de carros), a quien le dio dinero para gastos, pero cuando éste volvió faltaban un barril de vino blanco y otras vasijas, y 9 mulas; además no había socorrido a los peones ni pagado el pasto de las mulas, ni le entregó una suma que recibió por flete a tercero hecho con los carros. Izuel

\footnotetext{
54 Sumario iniciado en Colonia Francesa, 1902.

55 Ante la reincidencia, el juez dictaminó: “...resultando comprobados los malos tratamientos dados por Felipe Gamboa a su legítima esposa, por la declaración de los niños y por el sumario instruido en la comisaría de Colonia Francesa iniciado en marzo [...] por las mismas causas y fundamentos, de donde resulta reincidente el acusado de malos tratamientos a su esposa sin que haya dado pruebas de quererse corregir de este defecto, dando el mal ejemplo consiguiente a su familia, y siendo el deber de la justicia castigar estos desmanes para escarmiento y corrección de los que faltan a sus deberes, el infrascripto [sic] resuelve en este acto imponer a Felipe Gamboa la pena de sesenta días de arresto por reincidente en el delito de sevicia, condenándolo a la caución de no volver a ofender. Dejando a salvo los derechos de la esposa para que recurra donde corresponda en demanda de divorcio".

${ }^{56}$ Sumario iniciado en Colonia Francesa, 1901.
} 
consideraba que el comportamiento del capataz había sido "criminoso", y los testigos avalaron su denuncia. Ya en el juzgado, el fiscal dictaminó que por la cuantía la causa no correspondía a la justicia de paz, pero que antes de elevarla a instancia superior debía "intentarse previamente conciliación de las partes", lo que finalmente se logró. Ambos acordaron que en pago de los perjuicios ocasionados, Bilurón entregaría a Izuel 10 cabras de su señal y 30 días de trabajo, y cancelaría los gastos del juzgado; el trato quedaría sin efecto en caso de no cumplir. El arreglo fue beneficioso para el imputado, pues de lo contrario el caso habría pasado al juez del crimen siendo pasible de una pena mayor.

\section{Jueces, "abogados” y tinterillos}

Los jueces de paz debían ser argentinos o nacionalizados, tener como mínimo 25 años de edad y dos de residencia en el departamento cuando no fuesen hijos de la provincia, y no haber sido condenados por delito alguno. Igual que defensores y fiscales, pertenecieron a sectores medios de la sociedad local: empleados, pequeños propietarios o arrendatarios. También actuaron unos "apoderados" o representantes de un particular o una entidad pública (generalmente por cobro de deudas) dado que todo individuo que no tuviese incapacidad podía representar a otro aunque no fuese procurador de número, para lo que debía contar con poder general o especial. ${ }^{57}$ Se dispone de los siguientes datos de algunos de estos actores:

- Pascual Ruiz, juez de paz de 25 de Mayo; 51 años, español con ciudadanía argentina, casado, propietario en la villa, empleado. Anteriormente actuó en varios juicios como fiscal. ${ }^{58}$

- José Eugenio Santander, propietario en 25 de Mayo, subdelegado ${ }^{59}$ entre 1877 y 1882; en 1891 juez de paz especial por imposibilidad del titular; y juez de paz interino en $1892 .{ }^{60}$ Ocupó frecuentemente los cargos de defensor o de fiscal.

\footnotetext{
57 Los apoderados sólo podrían cobrar a su representado si mediaba un contrato escrito; asumían por aceptación del mandato todas las responsabilidades y estaban obligados a ejercer la representación hasta haber cesado legalmente; asimismo, eran responsables de los gastos judiciales mientras durase la representación, inclusive de los honorarios de los abogados.

58 Registro Cívico de 1904.

${ }^{59}$ Agente del Poder Ejecutivo Provincial en el departamento, con funciones policiales
} 
- David Arana, criollo nacido en Mendoza, 43 años, propietario en 25 de Mayo y Rama Caída. ${ }^{61}$ Juez de paz entre 1884 y 1889 , ejerció como notario público y fiscal especial.

- Nicasio Morales, 26 años, nacido en Buenos Aires, casado, empleado, domiciliado en 25 de Mayo en propiedad de M.A. González. Observaciones en el Registro Cívico Provincial de 1904: sabe leer y escribir "correctamente". Cumplió reiteradamente la función de "apoderado" en juicios por cobro de deudas, y fue fiscal.

Jueces y "abogados" no eran profesionales del derecho pero tenían una noción práctica adquirida en el asiduo desempeño de funciones en torno al juzgado, algo reconocido en ese ámbito y por la comunidad en general; sus conocimientos quedan de manifiesto en la citación que hacen de códigos y otras leyes, sobre todo en referencia a lo procesal. El dictamen del fiscal solía ser muy tenido en cuenta para determinar si el caso correspondía a la justicia de paz o de 1ํinstancia. Asimismo, la función del defensor fue central en la morigeración de la pena; era una tarea que, según se advierte, el designado realizaba a conciencia; solía referirse a "mi defendido". Fiscales y defensores eran libres de aceptar el cargo y cobraban honorarios por su labor.

Constan denuncias sobre el accionar de los jueces rurales del siglo XIX, función que hasta 1872 cumplieron los subdelegados, ${ }^{62}$ y para el período posterior se han encontrado críticas respecto de otra función que desempeñaban estos jueces: confección de padrones y presidencia de mesas electorales, tarea en que solían actuar según su filiación política en un período en que el fraude era lo corriente..$^{63}$ No se dispone, en cambio, de mayores quejas sobre el ejercicio de la función judicial por parte de los magistrados sanrafaelinos en el período acotado. Sin embargo consta una denuncia contra el mencionado Nicasio Morales, realizada ante el juez, aunque no hay resolución de este. Se trata de la exposición realizada

\footnotetext{
${ }^{60}$ Santander desconoció la autoridad municipal cuando lo reemplazó por otro y debió ser destituido. Concejo Deliberante de San Rafael, Acta de 4-9-1892.

61 Por Decreto de 22-9-1897se eximió de impuesto territorial a $1.635 \mathrm{~m} 2$ de viñedos de su propiedad.

62 Estos eran agentes territoriales del Ejecutivo y jefes de la policía en los departamentos. Sanjurjo, I. (2004). Op. cit.

${ }^{63}$ Sanjurjo, I. (2007 b). Op. cit.
} 
en 1911 por Isabel Rojas, según la cual 13 años antes la autoridad policial la había puesto al servicio de Morales, y dado que ahora era mayor de edad y aquél no le pagaba y la "trataba mal”, protestaba en presencia de testigos que la conocían desde los 10 años. Vale decir que estos actores pudieron aprovecharse de sus prerrogativas, pero el juzgado constituyó un espacio donde pudieron ventilarse también estas cuestiones.

Por último, hubo unos auxiliares $u$ oficiales de justicia que realizaban encargos del juzgado, como notificaciones o embargos; también peritos autorizados para realizar inspecciones "oculares", por ejemplo para avaluar daños, y mediadores ad hoc, etc. ${ }^{64}$ Eran tareas en las que solían alternarse los mismos individuos y por las que cobraban una suma determinada. Bastante frecuente por la cantidad de lesiones y heridas fue la intervención de peritos médicos (el ruso Teodoro Schestakow y el alemán Alfredo Hermann).

\section{Consideraciones finales}

La justicia de paz constituyó la única instancia judicial en el departamento de San Rafael a la que pudieron acudir los vecinos para solucionar sus controversias. El magistrado obró como un mediador que buscó en primer lugar la conciliación, y si esta no se conseguía fallaba según su "leal saber y entender" para dar a cada uno lo que correspondía, luego de haber escuchado a las partes y teniendo en cuenta los acuerdos verbales o escritos que estas hubiesen realizado. De tal modo esta justicia constituyó un instrumento fundamental para el desarrollo de la pequeña economía local, y para la conservación de otras múltiples y diversas relaciones de derecho en la sociedad local.

En materia penal, obraba primeramente la policía, y ante las habituales arbitrariedades que se producían en esta etapa la presencia ante el juez se muestra como un espacio de resguardo para los inculpados. Una característica que se advierte en la interacción entre justicia y policía es que las conclusiones a las que arribó esta luego de interrogar a los presuntos culpables, cómplices y testigos, no siempre fueron las mismas a las que llegó luego el juez, cuya decisión fue más clemente y seguramente más ajustada a los hechos.

\footnotetext{
64 En los distritos más lejanos, los decuriones -agentes de policía que podían incluso fallar en cuestiones de ínfima cuantía- obraban como auxiliares de justicia. 
Los excesos policiales parecen haber sido más frecuentes en las zonas lejanas a la villa cabecera departamental, y aplicados sobre todo a los sectores subalternos. En tanto, en las colonias se advierte un sentido comunitario que actuaba como control de la sociedad civil sobre los funcionarios públicos; una solidaridad vecinal que llevó incluso a denunciar hechos abusivos de la autoridad policial.

Se observa que los jueces resolvieron teniendo en cuenta circunstancias de edad de los actores, reincidencia o no en los hechos, distancia en que fueron cometidos los delitos y tiempo de prisión preventiva; y según el caso, actuaron con una actitud paternalista y salomónica que atendió a lo que consideraron el bien de los involucrados por sobre lo que podía ser estrictamente justo. Aún en casos penales pudo buscarse la conciliación si no mediaban hechos de sangre, pero en estos predominó la función correctiva. En los fallos, los expedientes muestran que no obstante la frecuente referencia a los códigos de procedimientos -cumpliendo con la prescripción de en lo posible "ajustar sus sentencias a derecho"- el entendimiento del juez fue relevante; se observa, entonces, la combinación de saberes específicos con discernimientos más amplios de búsqueda de la verdad y bien común, prevaleciendo este último criterio sobre la exactitud procedimental.

Estos magistrados, así como jueces y fiscales, pertenecían a los sectores medios de la sociedad, y su accionar tenía una legitimidad que provenía no solo de su nombramiento por las autoridades municipales y el gobierno provincial, sino por su pertenencia a la comunidad local y porque tenían un conocimiento del derecho que era reconocido, y que adquirieron en cargos de la administración provincial o el ejercicio de tareas en los juzgados. Se observa, entonces, que en torno a esta justicia existió una especie de división moral del trabajo y de funciones, por la que unas partes depositaban su confianza en las otras.

Por último, hay que decir que la gran mayoría de los expedientes con que se cuenta correspondieron a habitantes de las colonias, lo que sugiere que la población más distante (y sobre todo quienes carecieron de los medios para costearse un viaje hasta allí) tuvo dificultades para presentarse ante los juzgados, resolviendo sus controversias seguramente de otras maneras. En su ámbito de actuación, sin embargo, la justicia de paz constituyó un efectivo medio de resolución de los conflictos vecinales, al que pudieron recurrir individuos de diversos sectores sociales. Su aceitado funcionamiento es un indicio de consolidación, en 
esa zona de profundos cambios socioeconómicos, de una institución estatal sui generis, reglamentada para instalar modos de pacificación en las pequeñas relaciones de derecho de las comunidades locales.

\section{Referencias Bibliográficas}

Abásolo, Ezequiel (2004). "Las notas de Dalmacio Vélez Sárfield como expresiones del 'ius commune' en la apoteosis de la codificación, o de cómo un código decimonónico pudo no ser la mejor manifestación de la 'Cultura del Código'”. In Revista de Estudios Histórico-Jurídicos, n. 26, Valparaíso, p. 423-444.

Accatino Scagliotti, Daniela (1997). "El saber dogmático en nuestra cultura jurídica". In Revista de Derecho, n. 8, Valdivia: Universidad Austral de Chile, p.7-18.

Alonso Camacho, Omar (1997). "Conflictos jurisdiccionales en departamentos del sur mendocino: 1914-1970". Separata del Sexto Congreso Nacional y Regional de Historia Argentina, Buenos Aires: Academia Nacional de la Historia.

Augusto Marcó del Pont (1828). San Rafael, La región del porvenir, Mendoza: Impresiones Best.

Bustos Dávila, Nicolás (1983). "San Rafael. Ochenta años de la ciudad cabecera". In Los Andes, Mendoza.

Barreneche, Osvaldo (2007). “¿Lega o letrada? Discusiones sobre la participación ciudadana en la justicia de la ciudad de Buenos Aires durante las primeras décadas de independencia y experiencia republicana". In Palacio, Juan Manuel y Candioti, Magdalena (compiladores) (2007). Justicia, política y derechos en América Latina, Buenos Aires: Prometeo.

Barriera, Darío (2012). "Justicia de proximidad, pasado y presente, entre la historia y el derecho". In Polhis, n. 50.

Cantarelli, Andrea (2009). "Contratistas de plantación: agentes geográficos en los comienzos de la viticultura moderna en San Rafael, Mendoza, (1880-1914)". In Anuario del Centro de Estudios Históricos Prof. Carlos Segreti, v. 9, Córdoba.

Corva, M. Angélica (2005). "La Justicia de Paz en la Constitución de la provincia de Buenos Aires de 1873". In Revista de Historia del Derecho, n. 33, Buenos Aires.

Debener, Marcela (2002). "Estado, frontera e integración regional: Neuquén-Mendoza 18801950". In XIII Jornadas de Historia Económica, Mendoza, CDrom. 
Denis, Paul (1969). "San Rafael. La ciudad y su región". In Boletín de estudios geográficos, Vol XVI, № 64-65, Mendoza: Facultad de Filosofía y Letras-Universidad Nacional de Cuyo.

Díaz, Benito (1959). Juzgados de Paz de Campaña de la Provincia de Buenos Aires (18211854), La Plata: Universidad Nacional de La Plata- Facultad de Humanidades.

Garavaglia, Juan C. (1997). "Paz, orden y trabajo en la campaña: La justicia de Paz en Buenos Aires, 1830-1852". In Desarrollo Económico, n. 37, p. 241-262.

García de Madariga, Manuel (2002). La crítica al concepto liberal de justicia en la filosofía de Asladair Maclntyre. Memoria para optar al grado de doctor, Madrid: Facultad de Derecho, Universidad Complutense.

García Pino, Gonzalo (2001). "La idea de derechos en Alasdair Maclntyre y Charles Taylor: un contrapunto comunitarista". In Revista Ciencia Política, Vol. XXI, n. 1, p. 3-24.

Larrea, Basilio y Benzoni, Bernardo (compiladores) (1925). Compendio de leyes usuales de la Provincia con todas las modificaciones introducidas hasta el 30 de diciembre de 1924, t. XVIII, Mendoza: Publicación Oficial.

Hespanha, Antonio (1993). La Gracia del Derecho. Economía de la Cultura en la Edad Moderna, Madrid: Centro de Estudios Constitucionales.

$\overline{\text { Madrid: Taurus. }}$

(1989). Vísperas del Leviatán. Instituciones y poder político. Portugal, siglo XVII,

Macintyre, Asladair (1999). "Prefacio". In Animales racionales y dependientes, Barcelona: Paidos.

(2004). Tras la virtud, Barcelona: Crítica.

Masini Calderón, José L. (1985). Mendoza y sus tierras y frontera del sur entorno a 1880 (1875-1885), Mendoza.

Maza, Juan I. (1985). Malargüe y su historia, Mendoza.

Mijangos, Pablo (2010). "La historiografía jurídica mexicana durante los últimos 20 años (Primera de dos partes)", Documentos de trabajo de CIDE, n. 69, México.

Palacio, Juan Manuel (2004), La paz del trigo. Cultura legal y sociedad local en el desarrollo agropecuario pampeano (1890-1945), Buenos Aires: Edhasa. 
(2005-2006). "Hurgando en las bambalinas de la paz del trigo: algunos problemas teórico-metodológicos que plantea la historia judicial”. In Quinto Sol, n. 9-10, Santa Rosa-La Pampa, p. 99-124.

Paz Trueba, Yolanda (2008). "La justicia en una sociedad de frontera: conflictos familiares ante los juzgados de paz. El centro sur bonaerense a fines del siglo XIX y principios del XX". In Historia Crítica, n. 36, Bogotá, p. 130-149. URL http://redalyc.uaemex.mx/src/inicio/ ArtPdfRed.jsp?iCve=81111930007 Consultado7-3-2012.

Sanjurjo de Driollet, Inés (2004). La organización político administrativa de la campaña mendocina del antiguo régimen al orden liberal, Buenos Aires: Instituto de Investigaciones de Historia del Derecho.

(2006). "Frontera indígena y colonización agrícola". In Richard Jorba, Rodolfo et al. La región vitivinícola argentina. Transformaciones del territorio, la economía y la sociedad, 1870-1914, Buenos Aires: Universidad Nacional de Quilmes Editorial, p. 233-282.

(2007). "Formación de una elite de inmigrantes y criollos en el departamento de San Rafael (Mendoza) y su incidencia en la política provincial en el prolegómeno de la sanción de la Ley Sáenz Peña". In Res Gesta, Rosario, p. 109-148.

(2010a). "Justicia de paz y cultura jurídica en el largo siglo XIX en Mendoza (Argentina). El caso del departamento de San Rafael en el sur provincial”. In Nuevo Mundo Mundos Nuevos, Debates. URL http://nuevomundo.revues.org/59257. Consultado 20-4-2012.

(2010b). "La institución de la justicia de paz: la resolución de controversias vecinales de menor cuantía en materia civil y comercial (San Rafael, Mendoza, 1900-1916)". In Revista de estudios histórico-jurídicos, n. 32, Valparaíso-Chile, p. 395-418. URL http:// http://www.scielo.cl/scielo.php?pid=S0716-54552010000100015\&script=sci arttext. Consultado 10-7- 2013.

Segundo Censo Nacional de la República Argentina, mayo 10 de 1895, t. I (1898), Buenos Aires: Taller Tipográfico de la Penitenciaría Nacional.

Sedeillan, Gisela (2005). "La pérdida gradual de las funciones policiales del Juzgado de Paz: la creación de la institución policial en Tandil 1872-1900”. In Anuario Segreti, n. 5, Córdoba.

Seghesso de López, Cristina (1985). "General Alvear, departamento del sur mendocino (antecedentes y primeros años de vida)", Separata del Congreso Nacional de Historia sobre la Conquista del Desierto, Buenos Aires: Academia Nacional de la Historia.

Tau Anzoátegui, Víctor (1977). La codificación en la Argentina, Buenos Aires: Instituto de Historia del Derecho Ricardo Levene. 
Tejedor, Carlos (1871). Curso de Derecho Criminal, 2 Parte, Buenos Aires: Librería de C. Yoli.

Yangilevih, Melina y Miguez, Eduardo (2010). "Justicia criminal y Estado en la frontera de Buenos Aires, "justicia criminal y Estado en la frontera de Buenos Aires, 1895-1880". In Boletín del Instituto de Historia Argentina y Americana Dr. Emilio Ravignani, n. 32, Buenos Aires, p. 107-137.

Yangilevich, Melina (2011). "La justicia de paz en la construcción estatal al sur del río Salado (Buenos Aires, 1ํㅡㄹ mitad del siglo XIX)". In Piazzi, Carolina (2011). Modos de hacer justicia. Agentes, normas y prácticas. Buenos Aires, Tucumán y Santa Fe durante el siglo XIX, Rosario: Prohistoria, p. 75-92.

Recebido para publicação em 02 de setembro de 2013.

Aprovado para publicação em 30 de setembro de 2013. 